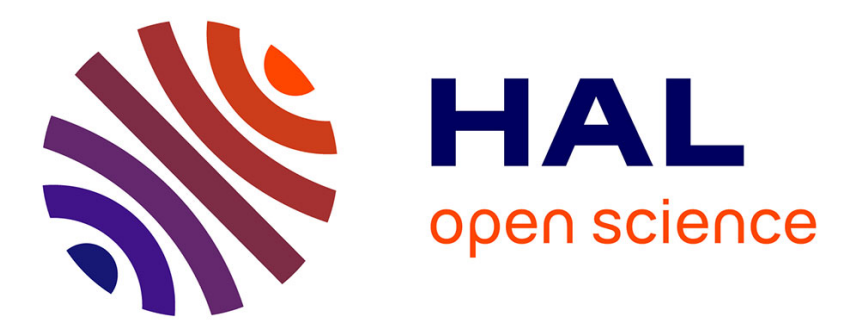

\title{
Hydrodeoxygenation Using Magnetic Induction: High-Temperature Heterogeneous Catalysis in Solution
}

Juan Manuel Asensio, Ana B Miguel, Pier-Francesco Fazzini, Piet W N M van Leeuwen, Bruno Chaudret

\section{- To cite this version:}

Juan Manuel Asensio, Ana B Miguel, Pier-Francesco Fazzini, Piet W N M van Leeuwen, Bruno Chaudret. Hydrodeoxygenation Using Magnetic Induction: High-Temperature Heterogeneous Catalysis in Solution. Angewandte Chemie International Edition, In press, 10.1002/anie.201904366 . hal02154800

\section{HAL Id: hal-02154800 \\ https://hal.science/hal-02154800}

Submitted on 13 Jun 2019

HAL is a multi-disciplinary open access archive for the deposit and dissemination of scientific research documents, whether they are published or not. The documents may come from teaching and research institutions in France or abroad, or from public or private research centers.
L'archive ouverte pluridisciplinaire HAL, est destinée au dépôt et à la diffusion de documents scientifiques de niveau recherche, publiés ou non, émanant des établissements d'enseignement et de recherche français ou étrangers, des laboratoires publics ou privés. 


\title{
Hydrodeoxygenation Using Magnetic Induction: High-Temperature Heterogeneous Catalysis in Solution
}

\author{
Juan M. Asensio, ${ }^{*[a]}$ Ana B. Miguel, ${ }^{*[a]}$ Pier-Francesco Fazzini, ${ }^{[a]}$ Piet W. N. M. van \\ Leeuwen $^{[a]}$ and Bruno Chaudret. ${ }^{*[a]}$
}

${ }^{\text {a} L P C N O, ~ U n i v e r s i t e ́ ~ d e ~ T o u l o u s e, ~ C N R S, ~ I N S A, ~ U P S, ~} 135$ avenue de Rangueil, 31077 Toulouse, France.

$\dagger$ Both authors contributed equally to this work

*Dr. Bruno Chaudret: chaudret@insa-toulouse.fr

*Dr Juan M. Asensio: asensior@ insa-toulouse.fr

ABSTRACT. Magnetic heating has recently been demonstrated as an efficient way to perform catalytic reactions after deposition of the heating agent and the catalyst on a support. Here we show that in solution, and in mild conditions of mean temperature and pressure, it is possible to use magnetic heating to carry out transformations that are otherwise performed heterogeneously at high pressure and/or high temperature. As a proof of concept, we chose the hydrodeoxygenation of acetophenone derivatives and of biomass derived molecules, namely furfural and hydroxymethylfurfural. These reactions are difficult, require using heterogeneous catalysts and high pressures and, to the best of our knowledge, have no precedent in a classical solution. Here, hydrodeoxygenation are fully selective while carried out in mild conditions (3 bar $\mathrm{H}_{2}$, moderate mean temperature of the solvent). The reason for this reactivity is the fast heating of the particles well-above the boiling temperature of the solvent and the local creation of hot spots surrounded by a vapour layer in which high temperature and pressure may be present. The ease of this technology may render practicable many organic transformations. 


\section{INTRODUCTION}

Catalytic transformations performed by heterogeneous catalysts are often carried out at high temperatures and/or high pressures because of their endergonic nature or high barrier of activation. Heat management is an issue in many of such gas solid reactions. In contrast, in solution, heat is easily transferred, but access to harsh conditions of temperature and pressure becomes an issue. An original approach that has not been explored in the literature for reactions taking place in solution is catalysis using magnetic heating. Magnetic heating has been applied in the field of cancer therapy (also known as magnetic hyperthermia) ${ }^{1-4}$ and more recently in heterogeneous catalysis. ${ }^{5-10}$ It is based on the fact that ferromagnetic materials release heat through hysteresis losses when subjected to a high-frequency alternating magnetic field. In this context, the use of magnetic nanoparticles (NPs) as heating agents may be a good strategy to improve the energy efficiency of reactions performed at high temperatures, as the heat is directly and homogeneously transferred to the medium without the need of heating the reactor walls. This methodology should also permit to reach very high local temperatures at the catalyst surface, creating "hot spots" in a "cold environment". This could allow local heating above the boiling point of the solvent, because the heat transfer by the solvent is slowed down by the formation of a vapor shell around the particle. ${ }^{11}$ (see Figure 1) The heating power of magnetic NPs is quantified by the specific absorption rate (SAR), which describes the amount of energy absorbed per unit of mass in the presence of an alternating magnetic field and is expressed in watts per gram $\left(\mathrm{W} \cdot \mathrm{g}^{-1}\right)$. Magnetically induced catalysis requires the design of catalytic systems that combine good heating power with high catalytic activity. For this purpose, in our group we have previously developed a method to coat Fe NPs with Ru through decomposition of an organometallic complex with hydrogen. ${ }^{6}$ More recently, we have reported the synthesis of $\mathrm{Fe}_{2.2} \mathrm{C}$ NPs displaying much higher heating properties than any previously described material. ${ }^{7}$ 

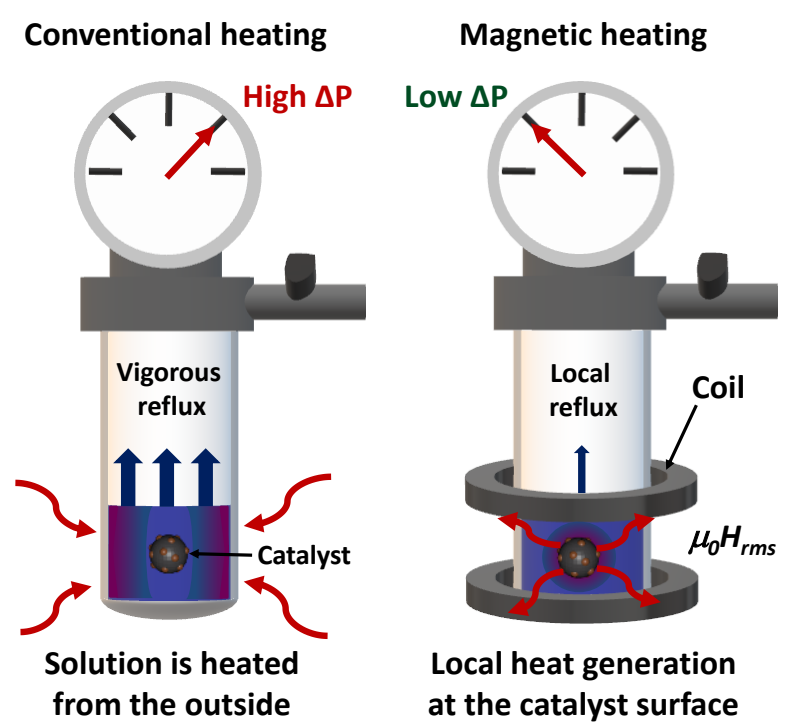

Figure 1. Comparison between conventional and magnetic heating.

Attempts to use magnetic heating for catalysis in solution have been reported so far by the group of Kirschning, ${ }^{12-14}$ who used steal beads or iron oxide NPs as heating agents encapsulated into silica. More recently, Rebrov and co-workers prepared modified $\mathrm{NiFe}_{2} \mathrm{O}_{4}$ materials that were used in amide synthesis, ${ }^{15-16}$ and Berenguer-Murcia and co-workers prepared magnetic nanoparticles encapsulated in zeolites which were used for isomerization of citronellal. ${ }^{17}$ To the best of our knowledge however, there are no reports in the literature of hybrid functional materials displaying high heating powers, in which a close contact between the heating agent and the catalyst may allow one to perform high-temperature catalysis in solution. One reaction of interest for biomass valorization that has been gaining a lot of attention during the past years for accessing to platform molecules and tailor-made fuels, is the catalytic hydrodeoxygenation of carbonyl groups, ${ }^{18-23}$ which yields the corresponding alkyl derivatives in a single step. ${ }^{24-26}$ This reaction is carried out under heterogeneous conditions at high pressures of $\mathrm{H}_{2}$.

Advances in hydrodeoxygenation have been reported that focused on the development of new heterogeneous catalysts based on $\mathrm{Ru}, \mathrm{Pd}_{\text {or }} \mathrm{Pt}^{27-31}$ and recently, Offner-Marko et al. designed a heterogeneous catalyst composed of bimetallic Fe-Ru NPs that can selectively 
hydrodeoxygenate aromatic substrates without reducing the aromatic rings, even at a pressure of $\mathrm{H}_{2}$ of 50 bar. $^{31}$ In this context, a first model reaction would be the hydrodeoxygenation of acetophenone catalyzed by $\mathrm{Ru}$ nanoparticles ( $\mathrm{Ru}$ NPs) even if Ru NPs are good catalysts for the hydrogenation of aromatic rings at room temperature, ${ }^{32}$ an undesired side-reaction in the hydrodeoxygenation of aromatic ketones..$^{29,33}$

In this paper, we explore the viability of magnetic heating in solution for the hydrodeoxygenation of aromatic and aliphatic ketones. The strategy followed is the synthesis of FeC@Ru NPs which combine the high heating power of $\mathrm{Fe}_{2.2} \mathrm{C}$ NPs with the high catalytic activity of $\mathrm{Ru}$ NPs. Then, after optimization of the reaction conditions for the hydrodeoxygenation of acetophenone and its derivatives, the reaction was extended to furfural and hydroxymethylfurfural under low $\mathrm{H}_{2}$ pressures (3 bar).

\section{RESULTS AND DISCUSSION}

$\mathrm{Fe}_{2.2} \mathrm{C}$ NPs with a mean size of ca. $14-15 \mathrm{~nm}$ were prepared following a recently described procedure (see Experimental Section). ${ }^{7,34}$ The particles display SAR values of $\sim 2100 \mathrm{~W} \cdot \mathrm{g}^{-1}$ measured at a $\mu_{0} H_{r m s}$ of $47 \mathrm{mT}$ with a fixed frequency of $93 \mathrm{kHz}$ (see Fig S1-7). The FeC@Ru NPs 1 were prepared through two-step decomposition of 0.033 equivalents of $\mathrm{Ru}_{3}(\mathrm{CO})_{12}$ under 1 bar $\mathrm{H}_{2}$ in the presence of $\mathrm{Fe}_{2.2} \mathrm{C}$ NPs (see Scheme 1 and experimental section for details). After the first decomposition, some small Ru seeds were observed at the surface of the $\mathrm{Fe}_{2.2} \mathrm{C}$ NPs by Transmission Electron Microscopy (TEM) and Energy Dispersive X-Ray Spectroscopy (EDX, see Fig S8). Then, a second decomposition of $\mathrm{Ru}_{3}(\mathrm{CO})_{12}$ was performed under the same conditions. 


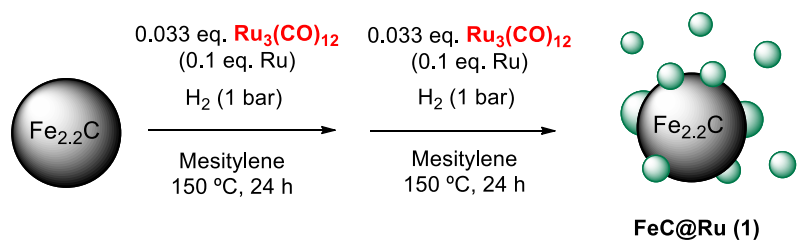

Scheme 1. Synthesis of FeC@Ru NPs 1.

NPs 1 were characterized by Scanning Transmission Electron Microscopy (STEM), High Angle Annular Dark Field (STEM-HAADF) and EDX, (see Figure 2 and Fig S9). Ru NPs of ca. 3-4 nm were deposited as islands on the surface of the $\mathrm{Fe}_{2.2} \mathrm{C}$ NPs. In addition, some $\mathrm{Ru}$ NPs that could not be removed after washing with toluene were still observable on TEM micrographs in the vicinity of the FeC@Ru NPs. NPs 1 were further characterized by all the common techniques. A considerable drop of SAR to $380 \mathrm{~W}^{\cdot} \mathrm{g}^{-1}(47 \mathrm{mT}, 93 \mathrm{kHz})$ was observed after introduction of Ru which is likely linked to NPs agglomeration (see Fig S10). ${ }^{34}$ The XRD diffractogram evidences the presence of $h c p-\mathrm{Fe}_{2.2} \mathrm{C}, h c p-\mathrm{Ru}$ and $b c c-\mathrm{Fe}(0)$ (see Fig $\mathrm{S} 11$ ). The presence of $\mathrm{Fe}(0)$ is likely due to hydrogenation of $\mathrm{Fe}_{2.2} \mathrm{C}$ to form methane in a $\mathrm{H}_{2}$ atmosphere, hence regenerating $\mathrm{Fe}(0) .{ }^{35}$ Magnetic characterization by Vibrating Sample Magnetometry (VSM) showed a decrease of both the saturation magnetization $\left(\mathrm{M}_{\mathrm{s}}\right)$ from $169 \mathrm{~A}^{\prime} \mathrm{m}^{2} \mathrm{~kg}^{-1}$ in $\mathrm{Fe}_{2.2} \mathrm{C}$ to $160 \mathrm{~A}^{\cdot} \mathrm{m}^{2} \cdot \mathrm{kg}^{-1}$, and the coercive field $\left(\mathrm{H}_{\mathrm{c}}\right)$ from $100 \mathrm{mT}$ to $70 \mathrm{mT}$, as expected for the introduction of a non-magnetic material (see Fig S12). Finally, the NPs were also characterized by ICP-MS (see Experimental Section). 

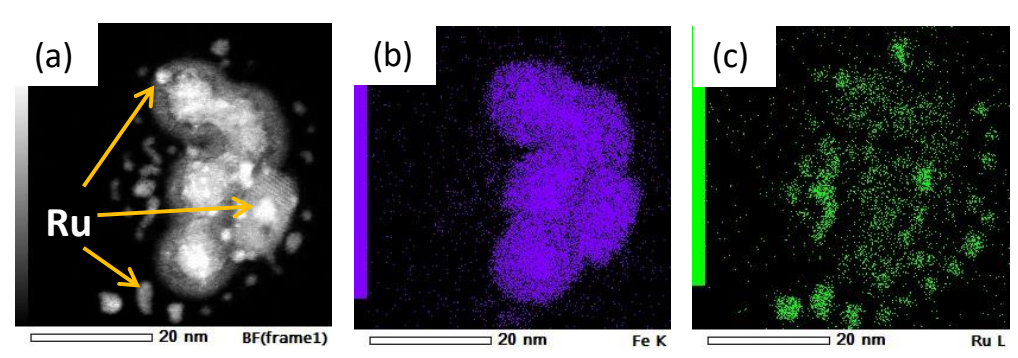

Figure 2. (a) STEM-HAADF (High angle annular dark field) image of NPs 1 and (b-c) EDX mapping of NPs 1 showing the elements (b) Fe and (c) Ru.

NPs $1(0.25 \mathrm{~mol} \% \mathrm{Ru})$ were used in the catalytic hydrodeoxygenation of acetophenone with $\mathrm{H}_{2}$ in mesitylene after application of an alternating magnetic field at a fixed $f$ of $300 \mathrm{kHz}$. Mesitylene was chosen as reaction medium because of its high boiling point. Few seconds after switching on the coil, the NPs get aligned along the direction of the magnetic field to form "chains" (see Fig S13) and some bubbling can be observed. After 2 minutes, the local medium near the NPs is under reflux ( $\mathrm{T}_{\text {boiling }}$ of mesitylene $=165^{\circ} \mathrm{C}$ ), although the pressure increase is only of 0.4 bars. Indeed, the external T measured with an IR camera was of ca. $150-160{ }^{\circ} \mathrm{C}$. This clearly indicates that the local temperature at the surface of the catalyst when the magnetic field is applied should be well above $165^{\circ} \mathrm{C}$. The NPs were characterized by HR-TEM after the reaction showing a high agglomeration, probably due to the high temperatures used (see Fig S14).

$\mathrm{Fe}_{2.2} \mathrm{C}$ NPs were not active in the reaction at a $\mu_{0} H_{r m s}$ of $80 \mathrm{mT}$ (entry 1, Table S1). In contrast, NPs 1 showed high activities under the same reaction conditions. Interestingly, ethylbenzene was observed as the only reaction product (100\% selectivity in all cases) and neither intermediates nor hydrogenation of the aromatic ring was observed. In a different experiment, $\mathrm{Ru}$ NPs with a mean size of $3 \mathrm{~nm}$ stabilized by heptanol were prepared using a described procedure. ${ }^{36}$ The Ru NPs were used as catalyst in combination with $\mathrm{Fe}_{2.2} \mathrm{C}$ NPs as heating agent. After performing the reaction at a $\mu_{0} H_{r m s}$ of $63 \mathrm{mT}$, a conversion of only $9 \%$ of acetophenone 
was obtained, while we observed a $3 \%$ yield of cyclohexylethan-1-one resulting from the hydrogenation of the aromatic ring, a reactivity typical of Ru NPs. The poor conversion emphasizes the importance of a close contact between the catalyst and the heating agent $(\mathrm{Ru}$ and $\mathrm{Fe}_{2.2} \mathrm{C}$ respectively). Finally, a control experiment using 1 and classical heating with an oil bath at $200{ }^{\circ} \mathrm{C}$ led only to $9 \%$ conversion with a $\mathrm{H}_{2}$ pressure increase of 2.2 bar. It should be noted that when the reaction is heated by magnetic induction the pressure increase is only 0.4 bar. The formation of chains seems to be highly important for the performance of the catalyst since (i) they enhance the heating power of the $\mathrm{NPs}^{[12]}$ and (ii) they reduce the surface area of the catalyst, slowing down the heat transfer rate to the solution and facilitating the formation of a local heterogenous medium (see comment S1). Finally, NPs 1 were separated by decantation after $4 \mathrm{~h}$ of reaction at a $\mu_{0} H_{r m s}$ of $58 \mathrm{mT}$, and a second catalytic run was performed. A drop of conversion from $61 \%$ to $36 \%$ was observed, that we attribute to the agglomeration of the NPs. Using reaction conditions leading to moderate acetophenone conversion $\left(61 \% ; 4 \mathrm{~h}, 3\right.$ bar $\mathrm{H}_{2}$, $58 \mathrm{mT}, 300 \mathrm{kHz}$ ), we studied the influence of substituents in the 4-position of the aromatic ring (2a-8a). The presence of electron-donating groups led to high conversions whereas electronwithdrawing groups induced lower conversions than those for unsubstituted acetophenone (Table 1). This may be explained by the fact that increasing the electronic density favors the coordination of the substrate to the hot metallic center, which we tentatively propose as the ratelimiting step. The Hammett plot for the reaction assuming a first reaction order for the parasubstituted derivates would agree with this hypothesis, as the negative $\rho$ value of -2.3 indicates the generation of positive charge in the substrate (see Fig S15).

For benzylideneacetone, hydrogenation of the alkene group is first observed (9a, entry 8) and after 24 hours, the ketone group is hydrogenated to give the alcohol as the major product (56\% yield, entry 10), with very low yields of the dehydration products ( $7 \%$ yield for the mixture of the $Z$ and $E$ alkenes and $8 \%$ yield for the alkane). The observation of the alcohol as the main 
reaction product agrees with a multi-step reaction mechanism (hydrogenation-dehydrationhydrogenation). Upon increasing the catalyst loading to $1 \mathrm{~mol} \%$ of $\mathrm{Ru}$, we found after 24 hours a $100 \%$ conversion with $n$-butylbenzene as the main reaction product ( $85 \%$ yield, entry 11 ). This reactivity is encouraging, as benzylideneacetone can serve as a model substrate of furfural acetone, a relevant platform molecule in the synthesis of biofuels. ${ }^{20}$

Table 1. Scope of substrates in the hydrodeoxygenation of ketones catalyzed by FeC@Ru NPs (1) in the presence of an alternating magnetic field.

Fntry


8b: 5

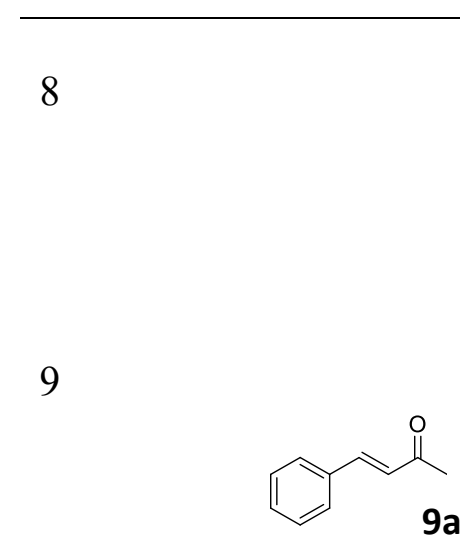

$9 a$

$10^{\mathrm{a}}$<smiles>CC(=O)CCc1ccccc1</smiles>

$9 b$<smiles>CC(O)CCc1ccccc1</smiles>

24

100

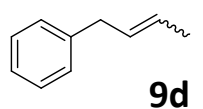

9d

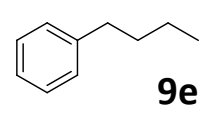

$24^{\mathrm{a}} \quad 100$
4

75

9b: 74

9c: 1

9b: 29

9c: 56

9d: 7

9e: 8

9b: 8

9c: 12

9d: 5

9e: 85

Reaction conditions: substrate :1.36 mmol, NPs 1: $5.0 \mathrm{mg}, 0.25 \mathrm{~mol} \%$ of Ru, mesitylene (5 $\mathrm{mL}), \mathrm{H}_{2}$ (3 bar), [a] $1.0 \mathrm{~mol} \% \mathrm{Ru}$.

Finally, we explored the viability of this reaction for biomass derivate model substrates. Thus, we performed the hydrodeoxygenation of furaldehyde (furfural) and 5-hydroxymethyl-2furaldehyde (HMF). These compounds are platform molecules derived from biomass that can be obtained from the respective dehydration of $\mathrm{C}_{5}$ and $\mathrm{C}_{6}$ sugars in the presence of an acidic catalyst. $^{37-38}$ Their hydrodeoxygenation products, 2-methylfurane (2-MF) and 2,5dimethylfurane $(2,5-\mathrm{DMF})$ are considered as good biofuel candidates. ${ }^{20}$ Such transformations are carried out industrially using high catalyst loadings, temperatures up to $280{ }^{\circ} \mathrm{C}$ and high pressures of $\mathrm{H}_{2}$ (from 10 to 50 bar). ${ }^{39-41}$ We first performed the hydrodeoxygenation of furfural 
in the presence of 3 bar of $\mathrm{H}_{2}$ in mesitylene using NPs $\mathbf{1}$ as catalyst with a $0.25 \mathrm{~mol} \%$ of $\mathrm{Ru}$ loading and a magnetic field of $58 \mathrm{mT}$ with a $f$ of $300 \mathrm{kHz}$ (see Scheme 2a). Under these conditions, a $38 \%$ conversion was found after 15 hours. The reaction products were a mixture of 2-furanmethanol (2-FFOH, 10\% yield) and 2-MF (28\% yield). When the catalyst loading was increased to $1.0 \mathrm{~mol} \%$ of $\mathrm{Ru}$, a $100 \%$ conversion was reached with a $100 \%$ selectivity towards 2-MF (see Scheme 2b). Similarly, HMF can be selectively transformed into 2,5-DMF under the same reaction conditions (Scheme 2c). It should be noted that hydrodeoxygenation occurs without the opening of the furan ring, which is a typical reaction observed for heterogeneous $\mathrm{Ru}$ catalysts. ${ }^{23}$

(a)

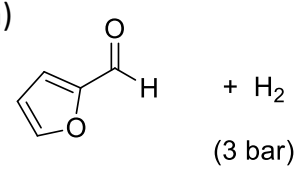

Conv. $\mathbf{3 8} \%$

(b)<smiles>O=Cc1ccco1</smiles>

Conv. $100 \%$

(c)

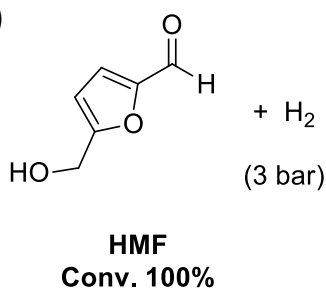

Conv. $100 \%$
FeC@Ru (1)

(Ru-0.25 mol\%)

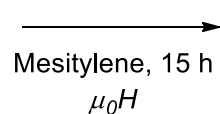

(58 mT, $300 \mathrm{kHz}$ )

FeC@Ru (1)

(Ru-1.0 mol\%)

Mesitylene, $15 \mathrm{~h}$

$$
\mu_{0} H
$$

$(58 \mathrm{mT}, 300 \mathrm{kHz})$

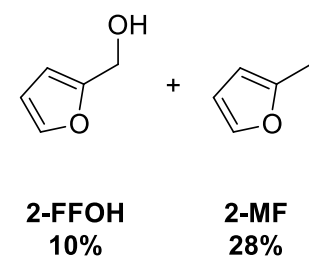

$10 \%$

$28 \%$
FeC@Ru (1)

(Ru-1.0 mol\%)

Mesitylene, $15 \mathrm{~h}$

$\mu_{0} \mathrm{H}$

(58 mT, $300 \mathrm{kHz}$ )

Scheme 2. Hydrodeoxygenation of biomass platform molecules catalyzed by NPs 1 . Hydrodeoxygenation of furfural using (a) $0.25 \mathrm{~mol} \%$ and (b) $1.0 \mathrm{~mol} \%$ of Ru loading. (c) Hydrodeoxygenation of HMF. 


\section{CONCLUSIONS}

In this paper, we demonstrate that magnetic heating allows the performance of catalytic reactions in solution that are otherwise carried out at a gas-solid interphase involving high temperatures and high $\mathrm{H}_{2}$ pressures. As a proof of concept, selective hydrodeoxygenation of acetophenone has been performed using FeC@Ru NPs which combine the high heating power of the $\mathrm{Fe}_{2.2} \mathrm{C}$ NPs with the high activities of $\mathrm{Ru}$. Remarkably, the close contact between the heating agent and the catalyst promotes the reaction and considerably increases the activity of the catalyst. The reaction is highly selective and occurs without the hydrogenation of the aromatic ring, which may be explained by the high temperatures and/or the formation of the $\mathrm{Fe}-\mathrm{Ru}$ alloy during the catalysis. Magnetic heating has allowed us to perform hydrodeoxygenation reactions using low catalyst loadings and very low pressures of $\mathrm{H}_{2}$ ( 3 bar in all the cases studied), which can be of interest in terms of scalability of the process. Finally, furfural and HMF, two platform molecules derived from biomass, were successfully and very selectively transformed into the corresponding alkylfurans 2-MF and 2,5-DMF respectively. This may be of further interest to perform selective oxygen removal avoiding ring-opening of heterocyclic molecules. In conclusion, these results prove the high potential of magnetic heating of magnetic NPs for catalysis in solution and, in the context of biomass valorization, demonstrate that using this new approach, the reactions can be performed very selectively under much milder conditions, and remarkably, very low pressures of $\mathrm{H}_{2}$.

\section{AKNOWLEDGMENTS}

The authors thank ERC Advanced Grant (MONACAT 2015-694159) and IDEX/Chaires d'attractivité de l'Université Fédérale de Toulouse Midi-Pyrénées for financial support. 


\section{NOTES AND REFERENCES}

(1) Ortgies, D. H.; Teran, F. J.; Rocha, U.; de la Cueva, L.; Salas, G.; Cabrera, D.; Vanetsev, A. S.; Rähn, M.; Sammelselg, V.; Orlovskii, Y. V., et al. Optomagnetic Nanoplatforms for In Situ Controlled Hyperthermia. Advanced Functional Materials, 28, 1704434.

(2) Yu, J.; Chen, F.; Gao, W.; Ju, Y.; Chu, X.; Che, S.; Sheng, F.; Hou, Y. Iron carbide nanoparticles: an innovative nanoplatform for biomedical applications. Nanoscale Horiz. 2017, 2, 81-88.

(3) Perigo, E. A.; Hemery, G.; Sandre, O.; Ortega, D.; Garaio, E.; Plazaola, F.; Teran, F. J. Fundamentals and advances in magnetic hyperthermia. Appl. Phys. Rev. 2015, 2, 041302/041301-041302/041335.

(4) Abenojar, E. C.; Wickramasinghe, S.; Bas-Concepcion, J.; Samia, A. C. S. Structural effects on the magnetic hyperthermia properties of iron oxide nanoparticles. Prog. Nat. Sci.: Mater. Int. 2016, 26, 440-448.

(5) Chaudret, B.; Carrey, J.; Fazzini, P. F.; Kelsen, V.; Lachaize, S.; Meffre, A.; Mehdaoui, B.; Respaud, M. Chemical process catalysed by ferromagnetic nanoparticles, WO2014162099A1, 2014

(6) Meffre, A.; Mehdaoui, B.; Connord, V.; Carrey, J.; Fazzini, P. F.; Lachaize, S.; Respaud, M.; Chaudret, B. Complex Nano-objects Displaying Both Magnetic and Catalytic Properties: A Proof of Concept for Magnetically Induced Heterogeneous Catalysis. Nano Lett. 2015, 15, 3241-3248.

(7) Bordet, A.; Lacroix, L.-M.; Fazzini, P.-F.; Carrey, J.; Soulantica, K.; Chaudret, B. Magnetically Induced Continuous CO2 Hydrogenation Using Composite Iron Carbide Nanoparticles of Exceptionally High Heating Power. Angew. Chem., Int. Ed. 2016, 55, 1589415898.

(8) Mortensen, P. M.; Engbaek, J. S.; Vendelbo, S. B.; Hansen, M. F.; Oestberg, M. Direct Hysteresis Heating of Catalytically Active Ni-Co Nanoparticles as Steam Reforming Catalyst. Ind. Eng. Chem. Res. 2017, 56, 14006-14013.

(9) Varsano, F.; Bellusci, M.; La Barbera, A.; Petrecca, M.; Albino, M.; Sangregorio, C. Dry reforming of methane powered by magnetic induction. Int. J. Hydrogen Energy 2019, Ahead of Print.

(10) Wang, W.; Duong-Viet, C.; Xu, Z.; Ba, H.; Tuci, G.; Giambastiani, G.; Liu, Y.; TruongHuu, T.; Nhut, J.-M.; Pham-Huu, C. CO2 methanation under dynamic operational mode using nickel nanoparticles decorated carbon felt ( $\mathrm{Ni} / \mathrm{OCF}$ ) combined with inductive heating. Catal. Today 2019, Ahead of Print.

(11) Riedinger, A.; Guardia, P.; Curcio, A.; Garcia, M. A.; Cingolani, R.; Manna, L.; Pellegrino, T. Subnanometer local temperature probing and remotely controlled drug release based on azo-functionalized iron oxide nanoparticles. Nano Lett. 2013, 13, 2399-2406.

(12) Ceylan, S.; Friese, C.; Lammel, C.; Mazac, K.; Kirschning, A. Inductive heating for organic synthesis by using functionalized magnetic nanoparticles inside microreactors. Angew. Chem., Int. Ed. 2008, 47, 8950-8953.

(13) Ceylan, S.; Coutable, L.; Wegner, J.; Kirschning, A. Inductive Heating with Magnetic Materials inside Flow Reactors. Chem. Eur. J. 2011, 17, 1884-1893, S1884/1881-S1884/1818. (14) Hartwig, J.; Ceylan, S.; Kupracz, L.; Coutable, L.; Kirschning, A. Heating under HighFrequency Inductive Conditions: Application to the Continuous Synthesis of the Neurolepticum Olanzapine (Zyprexa). Angew. Chem., Int. Ed. 2013, 52, 9813-9817.

(15) Houlding, T. K.; Gao, P.; Degirmenci, V.; Tchabanenko, K.; Rebrov, E. V. Mechanochemical synthesis of TiO2/NiFe2O4 magnetic catalysts for operation under RF field. Mater. Sci. Eng., B 2015, 193, 175-180. 
(16) Liu, Y.; Cherkasov, N.; Gao, P.; Fernandez, J.; Lees, M. R.; Rebrov, E. V. The enhancement of direct amide synthesis reaction rate overTiO2@SiO2@NiFe2O4 magnetic catalysts in the continuous flow under radiofrequency heating. J. Catal. 2017, 355, 120-130.

(17) García-Aguilar, J.; Fernández-García, J.; Rebrov, E. V.; Lees, M. R.; Gao, P.; CazorlaAmorós, D.; Berenguer-Murcia, Á. Magnetic zeolites: novel nanoreactors through radiofrequency heating. Chemical Communications 2017, 53, 4262-4265.

(18) Corma, A.; Iborra, S.; Velty, A. Chemical Routes for the Transformation of Biomass into Chemicals. Chem. Rev. 2007, 107, 2411-2502.

(19) Bu, Q.; Lei, H.; Zacher, A. H.; Wang, L.; Ren, S.; Liang, J.; Wei, Y.; Liu, Y.; Tang, J.; Zhang, Q., et al. A review of catalytic hydrodeoxygenation of lignin-derived phenols from biomass pyrolysis. Bioresource Technology 2012, 124, 470-477.

(20) Leitner, W.; Klankermayer, J.; Pischinger, S.; Pitsch, H.; Kohse-Hoeinghaus, K. Advanced Biofuels and Beyond: Chemistry Solutions for Propulsion and Production. Angew. Chem., Int. Ed. 2017, 56, 5412-5452.

(21) Luska, K. L.; Migowski, P.; Leitner, W. Ionic liquid-stabilized nanoparticles as catalysts for the conversion of biomass. Green Chem. 2015, 17, 3195-3206.

(22) Khromova, S. A.; Smirnov, A. A.; Bulavchenko, O. A.; Saraev, A. A.; Kaichev, V. V.; Reshetnikov, S. I.; Yakovlev, V. A. Anisole hydrodeoxygenation over $\mathrm{Ni}-\mathrm{Cu}$ bimetallic catalysts: The effect of Ni/Cu ratio on selectivity. Appl. Catal., A 2014, 470, 261-270.

(23) Julis, J.; Leitner, W. Synthesis of 1-Octanol and 1,1-Dioctyl Ether from Biomass-Derived Platform Chemicals. Angew. Chem., Int. Ed. 2012, 51, 8615-8619, S8615/8611-S8615/8612.

(24) Furimsky, E. Catalytic hydrodeoxygenation. Appl. Catal., A 2000, 199, 147-190.

(25) Singh, A. K.; Jang, S.; Kim, J. Y.; Sharma, S.; Basavaraju, K. C.; Kim, M.-G.; Kim, K.R.; Lee, J. S.; Lee, H. H.; Kim, D.-P. One-Pot Defunctionalization of Lignin-Derived Compounds by Dual-Functional Pd50Ag50/Fe3O4/N-rGO Catalyst. ACS Catal. 2015, 5, 69646972.

(26) Cao, Y.; Ma, R.; Wang, N.; Wang, M.-Y.; Li, X.-D.; He, L.-N. Selective hydrodeoxygenation of lignin $\beta-O-4$ model compounds and aromatic ketones promoted by palladium chloride with acidic CO2/MeOH system. J. CO2 Util. 2018, 24, 328-333.

(27) Nimmanwudipong, T.; Runnebaum, R. C.; Block, D. E.; Gates, B. C. Catalytic Conversion of Guaiacol Catalyzed by Platinum Supported on Alumina: Reaction Network Including Hydrodeoxygenation Reactions. Energy Fuels 2011, 25, 3417-3427.

(28) Yan, N.; Yuan, Y.; Dykeman, R.; Kou, Y.; Dyson, P. J. Hydrodeoxygenation of LigninDerived Phenols into Alkanes by Using Nanoparticle Catalysts Combined with Bronsted Acidic Ionic Liquids. Angew. Chem., Int. Ed. 2010, 49, 5549-5553, S5549/5541-S5549/5513.

(29) Luska, K. L.; Migowski, P.; El Sayed, S.; Leitner, W. Synergistic Interaction within Bifunctional Ruthenium Nanoparticle/SILP Catalysts for the Selective Hydrodeoxygenation of Phenols. Angew. Chem., Int. Ed. 2015, 54, 15750-15755.

(30) Gonzalez, C.; Marin, P.; Diez, F. V.; Ordonez, S. Gas-Phase Hydrodeoxygenation of Benzaldehyde, Benzyl Alcohol, Phenyl Acetate, and Anisole over Precious Metal Catalysts. Ind. Eng. Chem. Res. 2016, 55, 2319-2327.

(31) Offner-Marko, L.; Bordet, A.; Moos, G.; Tricard, S.; Rengshausen, S.; Chaudret, B.; Luska, K. L.; Leitner, W. Bimetallic Nanoparticles in Supported Ionic Liquid Phases as Multifunctional Catalysts for the Selective Hydrodeoxygenation of Aromatic Substrates. Angew. Chem., Int. Ed. 2018, Ahead of Print.

(32) Breso-Femenia, E.; Chaudret, B.; Castillon, S. Selective catalytic hydrogenation of polycyclic aromatic hydrocarbons promoted by ruthenium nanoparticles. Catal. Sci. Technol. 2015, 5, 2741-2751. 
(33) Gonzalez, C.; Marin, P.; Diez, F. V.; Ordonez, S. Hydrodeoxygenation of Acetophenone over Supported Precious Metal Catalysts at Mild Conditions: Process Optimization and Reaction Kinetics. Energy Fuels 2015, 29, 8208-8215.

(34) Asensio, J. M.; Marbaix, J.; Mille, N.; Lacroix, L.-M.; Soulantica, K.; Fazzini, P.-F.; Carrey, J.; Chaudret, B. To Heat or not to Heat: a Study of the Performances of Iron Carbide Nanoparticles in Hyperthermia. Nanoscale 2019, DOI: 10.1039/C1038NR10235J

(35) Bordet, A.; Lacroix, L.-M.; Soulantica, K.; Chaudret, B. A New Approach to the Mechanism of Fischer-Tropsch Synthesis Arising from Gas Phase NMR and Mass Spectrometry. ChemCatChem 2016, 8, 1727-1731.

(36) Pelzer, K.; Philippot, K.; Chaudret, B. Synthesis of monodisperse heptanol stabilized ruthenium nanoparticles. Evidence for the presence of surface hydrogens. Z. Phys. Chem. 2003, 217, 1539-1547.

(37) Mamman, A. S.; Lee, J.-M.; Kim, Y.-C.; Hwang, I. T.; Park, N.-J.; Hwang, Y. K.; Chang, J.-S.; Hwang, J.-S. Furfural: hemicellulose/xylose-derived biochemical. Biofuels, Bioprod. Biorefin. 2008, 2, 438-454.

(38) Lecomte, J.; Finiels, A.; Moreau, C. A new selective route to 5-(hydroxymethyl)furfural from furfural and furfural derivatives over microporous solid acidic catalysts. Ind. Crops Prod. 1999, 9, 235-241.

(39) $\mathrm{Hu}, \mathrm{L} . ; \mathrm{Lin}, \mathrm{L} . ; \mathrm{Liu}, \mathrm{S}$. Chemoselective hydrogenation of biomass-derived 5hydroxymethylfurfural into the liquid biofuel 2,5-dimethylfuran. Ind. Eng. Chem. Res. 2014, 53, 9969-9978.

(40) Huang, Y.-B.; Chen, M.-Y.; Yan, L.; Guo, Q.-X.; Fu, Y. Nickel-Tungsten Carbide Catalysts for the Production of 2,5-Dimethylfuran from Biomass-Derived Molecules. ChemSusChem 2014, 7, 1068-1072.

(41) Jae, J.; Zheng, W.; Lobo, R. F.; Vlachos, D. G. Production of Dimethylfuran from Hydroxymethylfurfural through Catalytic Transfer Hydrogenation with Ruthenium Supported on Carbon. ChemSusChem 2013, 6, 1158-1162. 